\title{
8. Motivational resilience in the university system
}

\section{Silvia Sacchetti}

A disposition to find your colleagues' work 'interesting' is about the most important single attribute you can cultivate if you yourself want to be a good colleague.

(Brennan, 2004: 89)

\section{INTRODUCTION}

Academia has been going through a process of change, which some authors say is increasingly mimicking the aims, modalities and values of traditional business (Sugden, 2004; Wedlin, 2008; Grönblom and Willner, 2009; Wilson, 2009; Parker, 2011). In particular, the competition for funding has endorsed the use of specific incentive systems that are aimed at influencing the motivations of academics and the capacity of departments to obtain research funds. For the purpose of this work we shall think of academics as individuals who can contribute to the creation of novel explanations by means of enquiry, and comment on the possible implications that current incentive systems may have on academics' endurance to problematize situations, raise questions and look for possible answers. Specifically, we explore the elements of the domains that surround academics and how these interact with their motivations.

Across a number of disciplines, including management, psychology, sociology and economics, there is an overarching agreement on the fact that human motivations importantly shape the nature of social and economic action, determining the effectiveness of organizations and their activities. Approaches however differ, not least in their basic assumptions. Whilst in economics it has been conventionally assumed that individuals are motivated by wealth maximization (Brennan, 2004), theories of social psychology and organizational behaviour have addressed the relationship between individuals and context, emphasizing the role of non-economic motivational drivers (such as achievement, recognition, 
professional growth, interest in the task performed) for the fulfilment of basic needs, such as competence (the mastering of abilities such as learning and creativity), autonomy (the feeling that an act is connected to the individual's will and critical judgement) and relatedness (the feeling to belong or being connected to a group) (Deci and Ryan, 2000). These constructs help to understand some of the considerations presented in the chapter. Deci and Ryan $(1985 ; 2000)$ identified a major critical issue in the evolution of motivations. In contrast with external drivers, such as pay increase, intrinsic motivations have been argued to reflect the innate attitudes of the individual when performing an activity:

Perhaps no single phenomenon reflects the positive potential of human nature as much as intrinsic motivation, the inherent tendency to seek out novelty and challenges, to extend and exercise one's capacities, to explore, and to learn. ... The construct of intrinsic motivation describes this natural inclination toward assimilation, mastery, spontaneous interest, and exploration that is so essential to cognitive and social development and that represents a principal source of enjoyment and vitality throughout life. (Deci and Ryan, 2000: 70)

In line with social psychology approaches, in this work we recognize that explanations of the dynamics of motivations, including those of academics, require an understanding of the way in which individual motivations (exemplified as the intrinsic interest towards activities or by the pull of external drivers) evolve out of social and economic processes of interaction (exemplified by relationships with colleagues and paradigms within the discipline; or with the university organization and its incentive strategies).

The working hypothesis of this chapter is that individuals engage in a constant process of definition, achievement and critical assessment of their own aims. In doing so they interact with contextual conditions (Dewey, 1934). Motivations are the immaterial energy that is used for the pursuit and critical appraisal of valued objectives at each specific point in time. Motivations, therefore, can be considered as a specific type or resource in human action. We see them as inputs into processes as well as outputs, the idea being that motivations are not static but constantly evolving as individuals engage with the environment. Through action and interaction with the environment motivational energy, taken at any point in time, is subject to change, including dissipation and renewal. In particular, we build an analogy between motivations and energy-matter in thermodynamics, which serves the purpose of positioning the issue of motivational dissipation and renewal in academia. Given the nature of academia and its concern for scientific advancements, we assume that academic work is inherently aimed towards enquiry. We suggest that crucial in the renewal of motivational energy is access to an open environment 
where the critical appraisal of aims and values is supported by encouraging enquiry, imagination and creativity. In particular, based on experience and self-reflection, we argue that for the enquiry-led academic discovery is supported when, along the process, researchers can work in a space that welcomes the emergence of novel and critical approaches to academic activities (reflecting autonomy, relatedness and competence). ${ }^{1}$

At the same time, rather than looking at motivation renewal within a monolithic organizational context, we take a complex view of academia. Complexity requires decomposition. We therefore suggest a possible way to identify, within the university organization, specific subsystems and the interactions between pairs of subsystems. The utility of this approach, which is grounded on Simon's classic complex system theory, is that of identifying the flows of motivational energy from and to different subsystems and whether, within the same organization, subsystems differ in the way they contribute to motivational dissipation or renewal (Simon, 1973).

\section{SOME CONTEXTUAL CONDITIONS: PEER EVALUATION, PEER SUPPORT AND MULTIPLE APPROACHES}

As a way of introducing our analysis of motivational resilience within a complex system, we first look at some specific conditions in academia that can help to make sense of some of the circumstances that currently interact with academics and their motivations. In particular, in what follows we distinguish between peer evaluation and peer support as two academic institutions which influence academic activity and specifically research.

\subsection{Peer Evaluation}

Peer evaluation has a long history in academia. It determines access to faculty and legitimizes scientific work. If on the one hand peer judgement supports coherence of enquiry in those who have access to academia, yet on the other it also moulds the aspirations and choices of academics.

At an increasing rate across countries, higher education policy has embedded peer evaluation within the incentive system that guides the allocation of public resources. The system of institutional incentives works by allocating public funding to departments according to past outcomes and peer review, which mainly relies on publications. ${ }^{2}$ This process is not without contradictions. In a special issue of the American Journal of Economics and Sociology, the editors offer a critical perspective on the impacts of the use of citation indexes, bringing together a number of 
bibliometric and network studies that emphasize how heterodox economists are in fact disadvantaged with respect to mainstream economists (Elsner and Lee, 2010). Strong criticisms have emerged that are sufficient to raise, not least, a number of question marks on the validity of the measures applied to the ex-post evaluation of academic work:

[T]he International Mathematical Union, the International Council of Industrial and Applied Mathematics, and the Institute of Mathematical Statistics have argued in a joint report released in June 2008 that the belief that citation statistics are accurate measures of scholarly performance is unfounded. The use of such statistics is often highly subjective, the validity of these statistics is neither well understood nor well studied, and the sole reliance on citation data provides at best an incomplete and often shallow understanding of research (Adler, Ewing, and Taylor 2008: 2). In the same light, Bruno Frey and Katja Rost (2008: 1) found that publication and citation rankings do not effectively measure research quality and that career decisions based on rankings are dominated by chance. (Elsner and Lee, 2010: 1334)

Despite the doubts, the assessment system is at the moment based primarily on peer review and citations, with no hints towards a change in direction. On the contrary, an increasing number of countries are adopting similar criteria to support resource allocation in higher education. Postperformance evaluation of faculty have had a long-standing application in North America and the UK, and inspired policies have more recently in Australia, Belgium, Denmark, Italy, New Zealand and Norway. ${ }^{3}$ Universities have adopted different strategies in response to such policies. In the UK, for example, universities tend to submit for evaluation only a selection of work, and then allocate research funds to the same researchers whose work has been submitted for assessment. One implication is that the others, the excluded, as Meyer (2012) notices, are bounded to enter a spiral of lack of funding, thus jeopardizing future research, their own career or even their tenure (ibid.). ${ }^{4}$ Intrinsic motivation and research aspirations across the excluded can then be expected to decrease. More generally, when associated with access to the discipline or with particular benefits, peer review may favour extrinsic motivational drivers, particularly in younger academics. ${ }^{5}$ With reference to the UK performance evaluation system, for example, Larkin (1999) observes how young talents feel under pressure to choose research topics that are consistent with the interests of evaluation panels. Untenured scholars may opt for lines of enquiry that are more likely to be acknowledged within established approaches or funding bodies, with the aim of demonstrating their suitability for academic organizations.

As it is, we can expect the pursuit of novelty to be channelled by extrinsic drivers and eventually slowed down. In a piece with clear Schumpeterian 
flavour, McKenzie and Galar (2004) addressed the question of paradigm shifts, and argued that should novelty emerge, it would do so from the work of those who deviate from known methods. They argue that the extent to which academia leaves space for unknown paths to be undertaken and radical innovations to develop and thrive, determines the survival of deviants and the introduction of novel ideas. Like past performance evaluation based on publications, peer assessment of research projects may reflect a preference of research bodies for projects that minimize risk by using a good fit with prevailing disciplinary paradigms. Since novelty introduces issues and methodologies that may have not been tried before, funding bodies tend to privilege established research areas and methodologies. The risk aversion of funding bodies is also reflected in the allocation of research funds to established academics who can offer a track record of past performance in the discipline. Further challenges would come also from the role that policy makers play in identifying elements of research programmes and, therefore, of research priorities promoted to government funding bodies, as research programmes that appeal to policy makers constitute a way of attracting research grants, access career advancements or maintain tenure (Smith, 2012). ${ }^{6}$

\subsection{Multiplicity within Disciplines and Publics}

In fact, from a substantive point of view, the use of peer assessment for ex-post evaluation and project funding implies more than a selection of 'the most valuable work' within each discipline. It also implies a selection of questions, constructs and approaches within each discipline. When looking at the substantive elements of disciplinary work, multiple research programmes inevitably emerge, reflecting the diversity of perspectives through which academics formulate questions and approach the search for answers (Burawoy, 2005). For Burawoy (2005: 263), these reflect 'different types of publics and multiple ways to access them'. Especially across the social sciences but also, for example, in arts and humanities or in natural sciences such as health-related disciplines, research has also a stark public dimension. These involve addressing socially relevant issues, creating new categories, promoting and defending the value of the discipline in the eyes of society, which entail reciprocal communication between academia and its different publics:

We should not think of publics as fixed but in flux and that we can participate in their creation as well as their transformation. Indeed, part of our business as sociologists is to define human categories - people with AIDS, women with breast cancer, women, gays - and if we do so with their collaboration we create publics. The category woman became the basis of a public - an active, 
thick, visible, national nay international counter-public - because intellectuals, sociologists among them, defined women as marginalized, left out, oppressed, and silenced, that is, defined them in ways they recognized. (Burawoy, 2005: 265 - emphasis added)

From a multiple-approach/multiple-public point of view, peer assessment means also power to create or destroy publics by generating hierarchies of questions, problems, and modalities of communication. Peer assessment, from this stand, bears implications that go beyond academic motivations or the efficiency of the university organization. Rather, it impacts on the public role of academics who, through the choice of research programmes, can have an empowering (or disempowering) role for publics: for example, research that looks at academics and at their motivations in our particular case, is in fact turning academics into the specific public of their own research. Academics become a research category that constitutes the basis for recognizing and communicating the economic and social issues associated with their situations. ${ }^{7}$

What we suggest is that the openness of a discipline towards questions that are relevant for a multiplicity of publics can reinforce the researcher's interest by building on his/her experience and curiosity, thus contributing to renew motivational energy towards enquiry. This stand reveals a further connection between the allocation of research funds based on peer evaluation and the survival of multiple interests within each discipline, where the conservation and creation of a variety of approaches among academics contributes to discovering their motivations, as well as to discovering new publics.

\subsection{Peer Support}

We have argued that, since intrinsic motivations reflect the inherent interests of individuals, motivations to conduct scholarly work are favoured by the endorsement of multiple lines of enquiry. This process points to an interconnected evolutionary process that links disciplinary paradigms, academic motivations and publics across society. Think for example about the reciprocal influences between the assumptions of conventional economics (and management), its dominance in the discipline, and the way in which economic choices are taken and promoted across organizations, regions and nations in a way that stresses the particular needs and objectives of some (e.g. the elites of decision-makers across different industrial sectors) whilst denying those of others (e.g. workers, the unemployed, consumers, parents with children, young people, communities that rely on biodiversity for their survival, and so on). Much of the constructs that 
support conventional economic theories, for example, consider recessions as a physiological element of economies, with which a variety of affected publics has to live.

The creation of variety can benefit from a scholarly ethics that offers respectful criticism, or one that points to areas of development for the creative agent. Engagement with peers and peer support, rather than peer evaluation, is part of the process that transforms one initial intuition into a clear line of thought. This is the time during which the researcher thrives and expresses his/her 'creative intelligence' (Dewey, 1917). From this angle, peer support helps, first of all, the enquiry process and, through it, the researcher. The focus is not necessarily on the production of preplanned results, but on discovery, understanding and search for novel opportunities and experiences (Kirzner, 1989; Bianchi, 1998; F. Sacchetti, 2009; Sacchetti and Sugden, 2009a). Commenting on his research experience at the Public Choice Center between 1976 and 1983, Brennan remembers what made the Center the right place for academic enquiry, and explicitly refers to the 'big figures' that were able to shape the 'intellectual culture' of the place (in this case Brennan talks about the economist and political theorist James Buchanan). On the other hand, in departments where peers adopt a punitive attitude (for example in terms of nasty or disrespectful comments during seminars and debates), creativity may be stifled and replaced with 'timidity and extraordinary risk aversion':

[T]he Center was almost precisely the opposite. New ideas, even rather flaky ones, were treated hospitably. A good point at a seminar earned you more plaudits than a bad point earned you condemnation. And Buchanan had a delightful and wonderfully supportive characteristic of breaking in to say, 'Now that's interesting. Really interesting!' And the maker of said 'interesting point' would quietly glow, and think how he might be even more 'interesting' next time around. Buchanan would make such remarks not, I think, because he self-consciously set out to be supportive, but rather because he did find things 'interesting.' (Brennan, 2004: 88-89)

Similarly, Wallis et al. (2009: 125) have recently reinforced the role of leadership in 'the development of hope so that organizational members can sustain their commitments in the face of disappointments'. Similarly, reciprocal support amongst peers, open discussion, and pro-creative criticism can help creative agents to maintain their commitment towards enquiry, even in the face of disappointment, which typically arises for example after a journal rejection or when a project does not get funded. This eventuality is extremely frequent. In fact, although departments encourage publication in top journals, the acceptance rate is on average less than 10 per cent in first-tier, and 20 per cent in second-tier journals 
(Day, 2011). These percentages, as Day (2011) observes, give us an indication of the scale at which academics experience rejections and, as a consequence, identity threats, reduced commitment, exclusion and dropping out, which is not, she argues, necessarily an indication of lack of skill or ability. Research universities in general fail to address the problem. Those who have a professional social network that can support them are better positioned to turn rejections into higher quality work, thus renewing their intrinsic interest in academia.

Against the uncertainty of outcomes, and particularly of research outcomes, in fact, it was Hirschman (1982) who talked about 'in-process benefits' that individuals obtain from the activity itself, rather than from the surplus gained as the difference between the final outcome and the cost of running an activity (Olson, 1965). Too much pressure to produce answers, as in the current incentive system, provides extrinsic drivers but can also prompt non-cooperative attitudes and the use of worn-out research questions, thus decreasing novelty, as well as the magnitude of in-process benefits. When cooperation deteriorates or when noveltyseeking behaviour is not supported, researchers who obtain reward from the process may withdraw their commitment and step out of the system. Hirschman (1982) warns that commitment is not a permanent feature of individual behaviour, and that rather it can be withdrawn in the face of recurring disappointment, or when the hopes for change are repeatedly challenged by events. We have suggested that disappointment and risk aversion can be mitigated by a network of peers who respectfully encourage enquiry and the development of new ideas. In this way, researchers can renew their intrinsic motivations and, as a consequence, their commitment to academic enquiry.

\section{MOTIVATION AS ENERGY}

We have emphasized that academic researchers are, in general, subject to peer assessment, which strongly defines individual career advancements and the distribution of research funds to both departments and individuals, as well as the extent to which different social needs receive attention. Part of the reason is that the activities of academics are often difficult to monitor, whilst outcomes are easier to observe and control (Geuna and Martin, 2003). This may leave some degrees of freedom to academics in the choice of specific questions within established paths, but not so much in terms of time and legitimacy to explore novel questions, methods and behavioural patterns. Peer assessment, used in this way, can be a powerful way of planning research agendas, and act as the external force that 
shapes research choices, with potential effects on academics' motivations, behaviour and commitment.

The current central planning of outcomes subsumes control of the aims of academics. If academics depend on pre-defined objectives, the only space left for choice is how to best fit an unchangeable context, at least in the medium run. We have suggested that a strong influence of external interests in the definition of research agenda reinforces extrinsic motivational drivers. As this happens, new populations of academics, with different desires and associated values, can be expected to emerge, in line with existing incentives and entry-exit rules. In parallel, however, where academics continue to provide peer support to each other, the process of enquiry can be stimulated thus contributing to renew inherent motivations and commitment to enquiry.

Both extrinsic and intrinsic drivers can in fact contribute to renew motivational energy. However, the aims pursued and the associated values are different in the two cases: externally defined by the research bodies or within the prevailing paradigm in the first case, rather than critically assessed by the academic in the second. The challenge is to provide a perspective that clarifies how, in particular, intrinsic motivations can be kept alive, so that academic activities continue to reflect a genuine process of enquiry and critical appraisal of research objectives. How can motivational energy of the intrinsic type last under the multiple features of the university system? What variations in the academic population will current incentives stimulate? The search for an answer requires digging into the composite nature of academic activity, focusing on the interactions amongst its different domains.

A useful analogy, although by no means exhaustive of the reality of human motivations, we think, comes from physics. Earlier applied by Georgescu-Roegen (1976) to make sense of environmental problems, the idea of thermodynamics provides motivational energy with a temporal and spatial connotation. Georgescu-Roegen (1976) was the first to identify the essence of the relationship between the economy and the natural environment. He detached economic theory from the prevailing paradigm by introducing the idea of entropy: in nature, nothing is created or destroyed, but everything is transformed. The second law of thermodynamics, otherwise called 'entropy law', opened the way to the fact that energy-matter goes from an ordered to a disordered status, making some situations irreversible. ${ }^{8}$ The message for economists was that resources are scarce and bound to be transformed into forms that cannot be used, at the known and established state of technology. Likewise in the economy, for Georgescu-Roegen it appears simplistic to talk about circularity (or cycles) as if situations 
could reverse to initial conditions once disturbances have disappeared, without traces (ibid.).

Differently, and consistently with the approach of pragmatism and institutionalists, history matters and can shape the life experience of the individuals and society (Dewey, 1940; North, 1990). Likewise, motivations do not respond solely to circular self-contained flows of incentives and levels of effort. Motivations evolve, but not cyclically to go back and forth from an initial status or an optimal level of effort externally defined, but alongside a process of critical appraisal of the interactions between individual desires, actions and the environment. As Zamagni (1982) notices, the essential lesson of evolutionary dynamics is that once mutation has occurred it is impossible to go back. Processes change energy-matter, and likewise immaterial elements such as human motivation, but cumulatively rather than mechanically. ${ }^{9}$

By using the thermodynamics metaphor, we can think about what processes best ensure that the motivational basis of individuals, and academics in this particular case, is created and renewed. In so doing, the thermodynamics approach represents a parallel that we use for explicatory purposes, but should not be taken as an exact match of the nature of motivations, which are in their essence an immaterial aspect of individual action. We can argue that motivations, as an immaterial form of energy, can be subject to dissipation, but unlike exhaustible forms of energymatter, they can be stimulated and renewed over the life experience of the individual and across different domains. ${ }^{10}$ Like in thermodynamics, we focus on systems that are open to exchanges of energy with the environment, as suggested for example in Loasby (2003), Berger and Elsner (2007) and Adkisson (2010). Such a focus sheds light on the use of resources so that the individual motivational basis is not compromised, but constantly renewed through a motivational inflow. We have argued that, in academia, this is supported not so much by the promotion of some extrinsically oriented behaviour, but by the degree of openness of the disciplinary area and the research institution where the academic works. Seen from this angle, a resilient organizational system can be argued to be more efficient in preserving an adequate level of motivations than a non-resilient system (although, as suggested in the following section, the resilience of the system does not provide a sufficient condition for its population to reproduce).

\section{THE EVOLUTION OF MOTIVATIONAL ENERGY}

Figure 8.1 illustrates the cumulative causational cycle that explains the evolution of motivations by means of contextual interactions. Following Dewey 


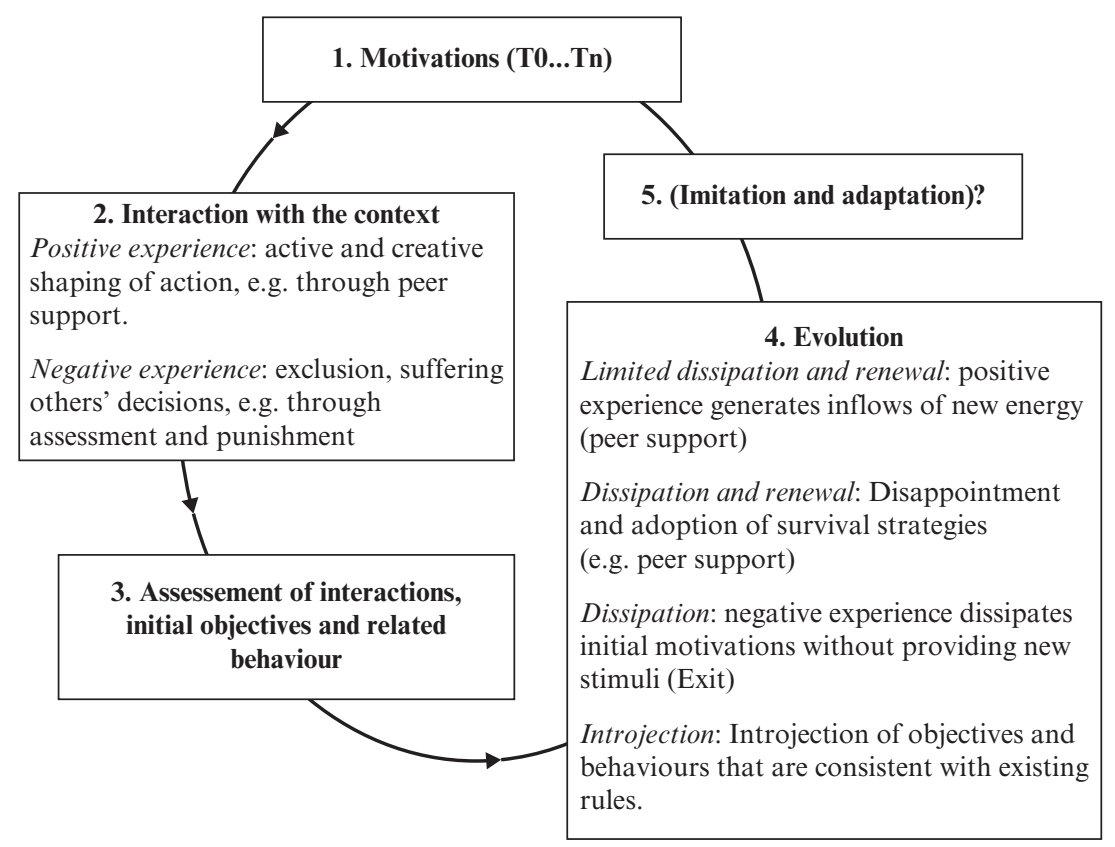

Figure 8.1 Motivational thermodynamic and resilience

(1934), it is experience that entails the whole complex set of interactions between the individual and the environment. Experience is either suffering or enjoying something happening within a context of which the individual is part (Kennedy, 1959). In particular, for Dewey the evolution of individual objectives, means and values is an elaboration of experience, including conscious reflection and interaction with others (Dewey, 1934). As valued objectives are the result of intrinsic determination, the energy that matters is the one that allows individuals to engage constantly with this learning process, which is, as a matter of fact, a process of enquiry involving the (life) objectives of the individual. We focus, therefore, on the renovation of intrinsic motivation. In striving and achieving the individual dissipates and renews this energy, learning about the importance of contextual elements and how these interact with his or her motivations and objectives (Dewey, 1917).

To apply the idea of experience to the dissipation and renewal of intrinsic motivations in academia, consider the following:

1. An academic is an actor within a population of agents occupying a specific niche defined by the subject area, the department/university, and the rules defined at policy level. 
2. Motivation, like energy, dissipates through interaction with the context at each period $i$.

3. Motivational dissipation (outflows of energy) and the behavioural patterns of some actors (cooperation vs competition) in period $i+1$ can be considered to be influenced by some actor's motivations and actions in period $i$ (e.g. an esteemed senior colleague), by the 'intellectual culture' shared by the population in that niche, and by the actor's previous history (Cf. McKenzie and Galar, 2004).

4. Intrinsic motivation is renewed when inherent interests and objectives enter directly into the making of individual choices.

5. Those niches where the population of actors offers respectful peer support (rather than assessment and punishment) and promote an intellectual culture of engagement and creativity are those where actors can shape objectives, where disappointment is minimized and intrinsic motivations renewed (inflows of energy).

6. Those niches where peer evaluation tends to reproduce existing ways of doing things (objectives and means are predefined), and promote a culture of instrumental enquiry, select actors that can introject external rules and shape their objectives accordingly (inflow of energy and selection of different objectives and behavioural patterns). The balance moves towards extrinsic motivation.

7. Conditions and behaviours that are successful in injecting new intrinsic motivational energy into actors may not be acknowledged and imitated if they conflict with the established system (path dependence and power asymmetries).

By experiencing diverse situations, more or less habitual, more or less uncertain and indeterminate, the individual can reassess valued objectives and discover what elements dissipate or renew his or her motivations. The enquiring mind, in particular, strives for discovery and would value a domain that allows for such a process to occur constantly (Kirzner, 1989; Bianchi, 1998). From this perspective, it is the possibility of exerting one's creativity, or to look constantly for novelty, that helps to renew intrinsic motivations. On the contrary, when there is no opportunity for reassessing the existent (in terms of research questions, methods, or rules incentivizing specific behaviours), motivation is destined to dissipation.

In academia positive experiences occur when the context allows the creative actor to explore novelty and shape activities, involving aspects of research, teaching and relations with colleagues. ${ }^{11}$ On the other hand, if activities are determined externally, the individual would experience exclusion from the definition of such aims, which may then erode the motivational basis for action. In both cases the individual can critically assess and 
learn about the impacts of contextual elements on his or her objectives and motivations and take further action, albeit with different implications with respect to the evolution of his/her motivational basis (Figure 8.1, box 4).

The worst-case scenario would be when no critical reassessment of the interactions and implications that derive from one's actions can be done (the cycle in Figure 8.1 would stop at box 2). When the individual lacks the opportunity, for whatever reasons (individual or contextual), to appreciate the implications of actions and events over his/her aims, then there can be no learning and no experience. This eventuality would be even more paradoxical in academia, where, in principle, enquiry is at the heart of what is valued, underpinning behaviours and activities.

\section{THE UNIVERSITY CONTEXT: DECOMPOSITION OF A COMPLEX DOMAIN}

We can now associate the reproduction (or 'stability' in the language of biology) of a population of individuals, such as academics, with the mutating status of the motivational basis, whose qualities (the balance between intrinsic and extrinsic drivers) change over time in response to interaction with the context. We refer to the process of evolution and adaptation that occurs in individuals to ensure the preservation of the necessary level of immaterial energy, or desire to carry out activities consistently with the enquiry principle.

We take now a step back and look at the context where the population of individuals carries out its experiences. Such a context would have in the first place to be resilient, that is, to maintain some order in the structure, or to absorb the stress coming from the inside and outside, through the selection of multiple optimal operating points within a complex environment. ${ }^{12}$ Among the features that reveal the degree of complexity of a system, as Simon (1973) observed, are several components that form the system, their diversity and their degree of interdependence.

In explaining the architecture of complex systems such as organizations, Simon (1973) focused on the advantages of their 'near decomposability', on the fact that the division of labour within the organization is such that activities that require faster and frequent coordination are grouped under the same subsystem, and that each subsystem, internally, carries out activities that require high levels of coordination, but relatively independently from other subsystems. This principle is recurrent in organizations as it ensures control and keeps costs at bay. Complementary, decomposable systems can adapt more effectively to contextual changes, as the crisis of an individual subunit is less likely to affect the fitness of the other units. At 


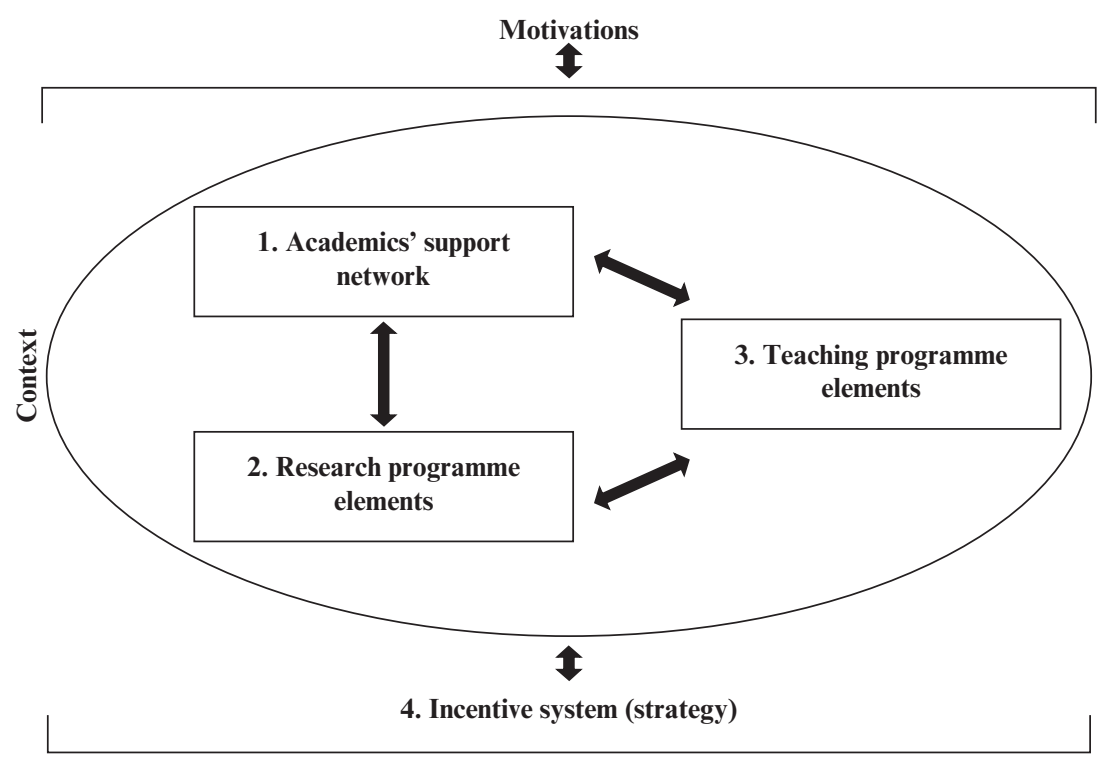

Figure 8.2 Near-decomposition of complex context

the same time, having relatively independent subsystems makes it easier to isolate and identify elements that may eventually touch the organization as a whole, favourably or unfavourably (Simon, 1973).

Following this line of reasoning, system resilience improves if there is not a single integral system but multiple subsystems, which can eventually temporarily supplement a dysfunctional subsystem. Academics in particular interact with a composite organizational and disciplinary context, which can be seen as the result of division of labour and power spheres within and across disciplines (Burawoy, 2005; Elsner and Lee, 2010; Smith, 2012). Within each subsystem academics carry out a different function. This set of functions originates, in turn, multiple motivational flows.

Following our analysis, we decompose the academic context into four fundamental domains: (1) the academics' support network, (2) research programme elements, (3) teaching programme elements, (4) incentives. Each of these domains needs to find an operating point in conjunction with all the others so that, overall, the system is sustainable (Figure 8.2). In doing so, each of the subsystems interacts with the academic's motivational basis.

The resilience of the university system, however, does not imply the stability of the population. Like in ecosystems, the university system may achieve resilience at the expense of the existing population's ability to 
Table 8.1 Matrix of relationships

\begin{tabular}{lllll}
\hline & 1 & 2 & 3 & 4 \\
\hline 1 & x & M & W & W \\
2 & M & X & W & - \\
3 & W & W & x & - \\
4 & M & S & W & x \\
\hline
\end{tabular}

Notes:

Subsystems: 1 = peer support network; $2=$ research programme elements; $3=$ teaching programme elements; $4=$ incentives.

Interactions: $\mathrm{S}=$ strong; $\mathrm{M}=$ moderate; $\mathrm{W}=$ weak; $-=$ undeterminded.

reproduce its own motivations. We have discussed, in these respects, some possible implications of performance evaluation practices.

Still, decomposing the organization has the advantage of showing where academics can in fact exert their critical action to counterbalance elements that, from other subsystems, may jeopardize their motivations. In line with Simon (1973), the intensity of interaction between pairs of academic domains clusters around strong, moderate and weak interactions. If we then look at the intensity of interactions across each individual pair we can understand with more clarity the extent to which each domain can impact on intrinsic motivation.

In Table 8.1 we suggest that strong to moderate interaction occur only between elements $4 \& 1,4 \& 2,2 \& 1$ and $1 \& 2$, that is, between the domains of peer support, research, and incentives. All the others are suggested as being of weak intensity. In general, we would argue that peer support can influence the nature of the research programme to some extent, by means of collaboration on common interests, shared values and approaches (Brennan, 2004; McKenzie and Galar, 2004; Sacchetti and Sugden, 2009 b). However, the extent to which collaborative work is possible depends also on the system of incentives, and despite traditional ideas of academic self-management, these are decided as part of a strategy-making process that not all academics can access.

Looking at the impact of the interaction between these three subsystems on intrinsic motivations, we have argued that peer support could contribute significantly to fulfilling needs of competence, autonomy and relatedness, to some extent balancing the potentially negative effects of a research system based on the ex-post evaluation of outcomes and monetary input from, for example, research grants. Here cooperation and support amongst peers go beyond the incentive system, and call directly for in-process benefits that can renew intrinsic motivations. 
In parallel, academics face pressures to innovate and deliver on teaching programmes that meet the demand of prospective students. Teaching elements may or may not overlap with the academic's research interests. In research institutions, moreover, external incentives prioritise research outcomes. It follows, as observed, that the process of selection within universities promotes those who have already established research competences. The allocation of teaching and related activities, then, is likely to follow a comparative advantage principle, by which academics who have less experience in attracting research funds are mostly allocated teaching responsibilities, thus leaving less time and attention for research.

This is expected to activate a cumulative causation process that may have a detrimental effect on those who have entered academia with research aspirations. On the other hand however, it could renew the energy sources of academics whose aims are accomplished mostly through teachingrelated activities. Still, teaching programmes can support research activities when academics can teach on their research interests and expertise, discuss ideas with students (some of whom may be future academics) and collaborate with colleagues on the substance of curricula, therefore possibly reinforcing the peer support system as well.

\section{CONCLUSIONS}

Solutions that have been thought to ensure the resilience of universities as organizations have prioritized, at a growing rate across national systems, an incentive system that serves the aim of revenue increase. However, we have argued that the individual adaptation to these contextual elements may endanger the stability of the population of academics and, in particular, of those whose motivations are consistent with the in-process benefits of enquiry.

Given this analysis, our framework has aimed at providing a way of understanding whether enquiry-led academics are an endangered species and how motivations can be kept alive. By taking a complexsystem approach to motivational resilience we have suggested that renewal depends also on the capacity of subsystems to compensate each other's functioning, and to learn from each subsystem's experience what elements support or do not support system resilience and population survival. We have hypothesized that the incentive strategy has the power to change attitudes and select motivations across the academic population. At the same time, the dissipation of inner motivations is going to be affected by the triangulation between incentives, the peer 
support network and research programme elements within their institution. The key to some degree of renewal could be in the strength of the support networks amongst peers, which in particular senior staff would have the responsibility to perpetuate as part of the core values of academic activity, not only through leading by example, but by providing the conditions, by means of strategic choices, for others to do the same.

The basic conclusion is that motivational dissipation is a negative function of the degree of articulation and openness of the academic system. Openness is reflected in the support given to the emergence and development of new ideas, and in the ability of the system to internalize emerging means and objectives by means of appropriate rules.

Whether our hypothesized interactions are reflected in general in the academic population requires empirical investigation. It demands further decomposition of each domain, an analysis of organizational characteristics on a case-by-case basis and their functionality or dis-functionality with respect to motivational resilience. This includes a consideration of the objectives, strategies and incentives put in place by the organization. What academia will be in the very long term also depends on the extent to which academics will perceive a shift in the locus that controls the formation of their aims. Multiple equilibria are likely to form, encompassing variety of objectives and motivational energy in the population of academics. Variety may be supported if universities depart from strategy isomorphism towards research, teaching and peer relationships. The quality of motivations and their resilience, more generally, will depend on the degree of flexibility with which academics, through their institutions, will be able to recognize multiple interests and attitudes, and to give themselves rules and implement strategies that leave space for the creative agent to engage in academic enquiry.

\section{ACKNOWLEDGEMENTS}

I would like to thank Francesco Sacchetti, Roger Sugden, Ermanno Tortia and the anonymous reviewers who have commented on a previous version of this work and to whom I am obliged for developments in the discussion on complex organizational systems. Thanks also to the participants in the 2009 Eunip Workshop on 'The role of academic research in territorial economic development processes' (Basque Institute for Competitiveness and University of Deusto, San Sebastian, Spain), where earlier reflections were discussed. 


\section{NOTES}

1. See Brennan (2004) for an analysis of esteem needs in academia.

2. An illustrative case of policy is provided by the ex-post performance measurement system in the UK (Geuna and Martin 2003). The normative purpose of the research assessment is defined by the UK higher education funding bodies of England, Northern Ireland, Scotland and Wales. The first assessment was completed in 1986 to attach the distribution of public funding to the performance of universities. In particular, the 2014 evaluation is principally related to measures of research outputs ( 65 per cent), alongside considerations of socio-economic impact ( 20 per cent) and environment (15 per cent) (HEFCE, 2009).

3. From a study of submissions and publication to the journal Science, Franzoni et al (2011) have found that although institutional incentives are correlated with the number of submissions, they are not significantly correlated with the number of publications. On the other hand, individual incentives in the form of career advancements are positively related to the publications and acceptance rate of submissions. These results point out that researchers submit their best work for publication when stimulated by a longterm recognition from peers, in the form of promotion, which includes clear monetary aspects too. Una tantum monetary incentives, like bonuses, on the other hand, crowd out quality for quantity and are detached from peer recognition. We could perhaps push the argument further and suggest that these findings would seem to be consistent with researchers obtaining satisfaction from peers' recognition, paired with stable monetary rewards. Higher levels of commitment and effort would follow, although competition for funding and recognition could reduce cooperation levels amongst academics.

4. Whereas New Zealand's institutional incentives would recognize everybody's work and give support to academic research at all levels (Meyer, 2012).

5. Challenges within disciplinary areas come also from the role of policy in identifying elements of research programmes. In exploring the field of health inequalities, Smith (2012), in particular, emphasizes the existence of multiple identities amongst academics, which reflect attitudes that attach value to research programmes defined in collaboration with policy makers on the one hand, and critical and challenging attitudes with respect to dominant discourses on the other. In this respect, the appeal of research programmes to policy makers is a way of attracting research grants, access career advancements or maintain tenure.

6. In exploring the field of health inequalities, in particular, Smith (2012), emphasizes the existence of multiple academic identities: those that value the collaboration with policymakers in the definition of research priorities, as opposed to those who adopt critical and challenging attitudes with respect to dominant discourses on the other.

7. See Dewey (1927) on the meaning of publics.

8. Jevons (1888) defines economics in terms of the mechanics of utility and individual interest. The irreversibility of the 'entropic arrow' is in clear contrast with the principles of mechanics that characterize the prevailing economic approach, defined by the rational maximizer who makes choices at the margin on the ground of pre-ranked preferences. Collectively, Pareto efficiency represents the economic criterion: a situation is optimal when it is impossible to augment the satisfaction of one individual without worsening that of somebody else. However, critical voices and policy action have emphasized that the maximization of individual self-interest through the market cannot ensure the preservation of natural resources over time, and have argued for the introduction of extra-market mechanisms which are better positioned to deal with the idea of limit that is attached to entropy.

9. Cf. Myrdal (1957), on the principle of circular cumulative causation

10. In analysing the metaphors of motivations, Weiner (1991) addresses the idea of energy distribution in Freudian psychoanalytic theory. He suggests that Freud's approach to motivations assimilates men to machines, where power is needed to carry out the desired actions. From this point of view, the principles of energy preservation have 
been applied to explain the negative impacts of inhibitory forces on psychological equilibrium.

11. Complementary to an understanding of environing elements, the learning experience pertains also to the discovery of personal characteristics, such as the value attached to specific desires, but also elements such as tenacity and the capacity to maintain attention and focus, which can contribute to renew one's motivational basis successfully (Wallis et al., 2009).

12. In biology, resilience is measured as the capability of the system to maintain some order in the structure, or to absorb the stress coming from the outside, through the selection of multiple optimal operating points within a complex thermodynamic context (Common and Perrings, 1992).

\section{BIBLIOGRAPHY}

Adkisson, R. V. (2010) 'The economy as an open system', in T. Natarajan, W. Elsner, and S. Fullwiler (eds), Institutional Analysis and Practice, New York: Springer, pp. 25-38.

Adler, R., J. Ewing and P. Taylor (2008) 'Citation statistics'. A Report from the International Mathematical Union in Cooperation with the International Council of Industrial and Applied Mathematics and the Institute of Mathematical Statistics, online at http://www.mathunion.org/fileadmin/IMU/ Report/CitationStatistics.pdf (accessed 30 September 2012).

Berger, S., and W. Elsner (2007). 'European contributions to evolutionary institutional economics: The cases of "cumulative circular causation" and "open systems approach". Some methodological and policy implications', Journal of Economic Issues, 41: 529-537.

Bianchi, M. (1998) (ed.) The Active Consumer. Novelty and Surprise in Consumer Choice. London: Routledge.

Brennan, G. (2004) Life in the putty-knife factory, American Journal of Economics and Sociology, 63 (1): 79-104.

Burawoy, M. (2005) 2004 American Sociological Association presidential address: for public sociology. British Journal of Sociology, 56 (2): 259-294.

Common M. and C. Perrings (1992) 'Towards an ecological economics of sustainability', Ecological Economics, 6: 7-34.

Day, N. E. (2011) 'The silent majority: manuscript rejection and its impact on scholars', Academy of Management Learning and Education, 10 (4): 704-718.

Deci, E. L. and R. M. Ryan (1985), Intrinsic Motivation and Self-determination in Human Behavior, New York: Springer.

Deci, E. L. and Ryan, R.M. (2000), Self-determination theory and the facilitation of intrinsic motivation, social development and well-being. American Psychologist, 55 (1): 68-78.

Dewey, J. (1917). Creative Intelligence: Essays in the Pragmatic Attitude. Reproduced in D. Sidorsky (ed.) (1977) John Dewey, New York: Harper.

Dewey, J. (1927) The Public and its Problems, Denver, CO: Holt. Reproduced in J. A. Boydston (eds) (1988) John Dewey. The Later Works Volume 2: 1925-1927, Carbondale and Edwardsville: Southern Illinois University Press.

Dewey, J. (2005) Art as Experience, New York: Penguin, (originally published 1934).

Dewey, J. (1940) 'Time and individuality', reproduced in L. A. Hickman and 
T. M. Alexander (eds) (1998), The Essential Dewey, 1, Bloomington, IN: Indiana University Press, pp. 217-226.

Elsner, W. and F. S. Lee (2010) 'Editors' introduction', American Journal of Economics and Sociology, 69 (5): 1333-1334.

Franzoni, C., G. Scellato and P. Stephan (2011) 'Changing incentives to publish', Science, 333 (August): 702-703.

Frey, B. and K. Rost. (2008) Do rankings reflect research quality? Institute for Empirical Research in Economics, Working Paper No. 390, University of Zurich. http://www.iew.uzh.ch/wp/iewwp390.pdf (accessed 30 September 2012).

Georgescu-Roegen, N. (1976), Energy and Economic Myths, New York: Pergamon Press.

Geuna, A. and B. R. Martin (2003). 'University research evaluation and funding: an international comparison', Minerva, 41: 277-304.

Grönblom, S. and Willner, J. (2009). Destroying creativity? Universities and the new public management. In S. Sacchetti and R. Sugden (eds), Knowledge in the Development of Economies: Institutional Choices under Globalization. Cheltenham: Edward Elgar.

HEFCE (Higher Education Funding Council for England) (2009), 'Research excellence framework. Second consultation on the assessment and funding of research'. Policy development consultation, September 2009/38.

Hirschman, A. O. (1982) Shifting Involvements: Private Interests and Public Action, Princeton: Princeton University Press.

Jevons, W. S. (1888), The Theory of Political Economy. Library of Economics and Liberty. online at http://www.econlib.org/library/YPDBooks/Jevons/jvnpe.html (accessed 4 August 2011).

Kennedy, G. (1959), 'Dewey's concept of experience: determinate, indeterminate, and problematic', Journal of Philosophy, 56 (21): 801-814.

Kirzner I. M. (1989) Discovery, Capitalism, and Distributive Justice. Oxford: Basil Blackwell.

Larkin, M. J. (1999), 'Pressure to publish stifles young talent', Nature, 397 (6719): 467.

Loasby, B. J. (2003), 'Closed models and open systems', Journal of Economic Methodology, 10 (3): 285-306.

McKenzie, R. B. and R. Galar (2004) 'The importance of deviance in intellectual development', American Journal of Economics and Sociology, 63 (1): $19-49$.

Meyer, L. H. (2012), 'Negotiating academic values, professional responsibilities and expectations for accountability in today's university', Higher Education Quarterly, 66 (2): 207-217.

North, D. C. (1990), Institutions, Institutional Change and Economic Performance. Cambridge: Cambridge University Press.

Olson, M. (1965), The Logic of Collective Action. Cambridge: Harvard University Press.

Parker, L. (2011) University corporatisation. Driving redefinition, Critical Perspectives on Accounting, 22 (4): $434-450$.

Sacchetti, F. (2009), 'Quantity, quality and creativity' in S. Sacchetti and R. Sugden (eds), Knowledge in the Development of Economies: Institutional Choices Under Globalisation, Edward Elgar Publishing, pp. 249-265.

Sacchetti, S. and R. Sugden (2009a), 'Positioning order, disorder and creativity in research choices on local development', in S. Sacchetti and R. Sugden 
(eds) Knowledge in the Development of Economies. Institutional Choices under Globalisation, Cheltenham: Edward Elgar, pp. 269-288.

Sacchetti, S. and R. Sugden (2009b), 'The organization of production and its publics: mental proximity, market and hierarchies', Review of Social Economy, 67 (3): 289-311.

Simon, H. A. (1973), 'How complex are complex systems?' Proceedings of the Biennial Meeting of the Philosophy of Science Association, Vol. 1976/2: Symposia and invited papers, pp. 507-522.

Smith, K. (2012) 'Fools, facilitators and flexions: academic identities in marketised environments', Higher Education Quarterly, 66 (2): 155-173.

Sugden, R. (2004), 'A small firm approach to the internationalization of universities: a multinational perspective', Higher Education Quarterly, 58 (2-3): 114-135.

Wallis, J., B. Dollery and L. Crase (2009), 'Political economy and organizational leadership: a hope-based theory', Review of Political Economy, 21 (1): 123-143.

Wedlin, L. (2008), 'University marketisation: the process and its limits', in L. Engwall and D. Weaire (eds), The University in the Market. Colchester: Portland Press, pp. 143-153.

Weiner, B. (1991) 'Metaphors in motivation and attribution', American Psychologist, 46 (9): 921-930.

Wilson, J. (2009) Higher education and economic development: do we face an intertemporal trade-off? In S. Sacchetti and R. Sugden (eds), Knowledge in the Development of Economies: Institutional Choices under Globalization. Cheltenham: Edward Elgar.

Zamagni, S. (1982) 'Introduzione', in Georgescu-Roegen, Energia e miti economici, Torino (IT): Boringheri. 